\title{
Effect of instructions on memory for temporal order
}

\author{
NINA P. AZARI, BRYAN C. AUDAY, and HENRY A. CROSS \\ Colorado State University, Fort Collins, Colorado
}

\begin{abstract}
We conducted an experiment to test whether temporal-order encoding meets one of the criteria for automaticity (Hasher \& Zacks, 1979). Sixty-four college-age students were assigned to four different instructional groups: (1) Control, (2) Judgment of Recency, (3) Judgment of Position, and (4) Recall. The subjects were presented with a serial list of words on a computer screen. Prior to list presentation, the subjects received one of the instructional sets. Subsequent to list presentation, two temporal order memory tests were administered. No differences were found among the four instructional groups on the retention measures. The results suggest that memory for temporal order satisfies one of the criteria for an automatic process. Current criticisms of incidental instructional sets as well as the criteria that define an automatic process are discussed and considered as they apply to the present study.
\end{abstract}

Memory for temporal order has been investigated most recently with respect to three major issues: (1) identifying the processes involved in temporal-order encoding, (2) determining whether such processes are automatic or effortful, and (3) choosing the criteria to be used to determine whether a given process is automatic or effortful. It has been suggested that temporal-order encoding is established automatically, being resistant to intention and practice (Hasher \& Zacks, 1979; McCormack, 1981; Toglia \& Kimble, 1976; Tulving \& Madigan, 1970; Tzeng, 1976; Zimmerman \& Underwood, 1968). Conversely, there is evidence that indicates that a certain amount of effort is needed for the encoding of time and order information (Michon \& Jackson, 1984; Tzeng \& Cotton, 1980; Zacks, Hasher, Allen, Sanft, \& Rose, 1984). The purpose of this study was to address the question of the nature of encoding for temporal order. However, our specific aim was to test only one criterion for automaticity (Hasher \& Zacks, 1979), that is, whether instructions affect temporal memory.

Zimmerman and Underwood (1968), invoking a freerecall paradigm, concluded that "to instruct $S$ to acquire such knowledge is merely to tell him to do something he would do anyhow"' (p. 307). Shortly thereafter, others spoke of temporal-order memory as being acquired "without any apparent 'cost' to the system"' (Tulving \& Madigan, 1970, p. 464), and that it "does not depend upon intentional processing”' (Toglia \& Kimble, 1976, p. 443). Further investigations have indicated invariance among differentially informed subjects (Hyde \& Jenkins, 1969).

Another dimension was later introduced to test the notion of the automaticity of encoding for temporal order.

Bryan C. Auday is presently at Gordon College, Wenham, MA. Address correspondence to Henry A. Cross, Department of Psychology, Colorado State University, Fort Collins, CO 80523.
Tzeng (1976) found that displaced rehearsals did not disrupt memory for order relationships. He and his colleagues summarized previous work on memory for temporal order wherein they claimed that such encoding is "automatic and seemingly effortless" (Tzeng, Lee, \& Wetzel, 1979, p. 54). To explain the processes involved, they proposed a study-phase retrieval model of temporal memory. The model dictates that information regarding position is established automatically as a result of an effortful rehearsal process. Thus, Tzeng et al. claimed that encoding of order relationships is initiated by a process that has become automatic by practice. They concluded that actual code assignment is an automatic byproduct of the study-phase retrieval process. Subsequent research has provided evidence for this theory (Auday, Sullivan, \& Cross, 1988; McCormack, 1982; Tzeng \& Cotton, 1980; Winograd \& Soloway, 1985).

Hasher and Zacks (1979) reviewed the research on automatic and effortful cognitive processes and provided comprehensive definitions of such. They called automatic those processes that are not affected by rehearsal or practice, developmental trends, other ongoing cognitive activities, the physical state of the subject, other attentional demands, or instructions. The processes that they claimed to be automatic are those that encode spatial, temporal, and frequency of occurrence information. It should be noted, however, that others have recently proposed new criteria for automaticity (Naveh-Benjamin \& Jonides, 1986; Sanders, Gonzalez, Murphy, Liddle, \& Vitina, 1987).

Recent findings have challenged the notion of automaticity for temporal-order encoding. For example, Zacks et al. (1984) found that subjects improved on temporalorder retention tests over three consecutive list presentations. Michon and Jackson (1984) manipulated an instructional variable and found that subjects who were specifically informed of later temporal-order retention tests 
performed better than those who were only told of a subsequent recognition test. Both studies called into question the automaticity of temporal-order encoding processes.

A test of the automatic nature of temporal-order encoding by studying the effect of manipulating an instructional variable at more than two levels was proposed. We hypothesized that an automatic temporal encoding process would be evident if there were no differences in performance among four instructional groups. Differences among the four groups could be interpreted as evidence for an effortful temporal-order encoding process.

\section{METHOD}

\section{Subjects}

Sixty-four introductory psychology students ( 28 males and 36 females) from Colorado State University received experimental course credit for participation.

\section{Apparatus}

The experiment was conducted in a laboratory room. All test stimuli were presented on an Apple IIe microcomputer. The monitor displayed white characters on a black background. Words were displayed inside a $5.5-\mathrm{cm}$-wide $\times 2.5-\mathrm{cm}$-high rectangular box that was centered on the screen.

\section{Materials}

Fifty-two words of AA frequency were selected from the Thorndike and Lorge (1944) word norms. All the words were four to seven letters in length, were minimally associated (Palermo \& Jenkins, 1964), and were homogeneous (4.33-6.73) in terms of imagery (Paivio, Yuille, \& Madigan, 1968). One test list of 48 randomly selected words was constructed, and two computer-generated randomizations were used. Four words were used as sample stimuli prior to the test list presentation.

\section{Tests}

Judgment of position (JOP) test. The 48 words of the test list were randomly typed on paper. The subjects were informed that the list had originally been divided into eight "blocks," each of which contained six words; for example, Block 1 contained Words 1 through 6 . Subjects were instructed to write beside each word the block number in which they thought the word had occurred.

Judgment of recency (JOR) test. The $\mathbf{4 8}$ test words were typed in 24 pairs on a sheet of paper. The subjects were instructed to circle the one word in each pair that they thought had occurred later in the list. The criteria for forming the pairs were: (1) pairs had to have either 1, 2 , or 4 intervening test words between them, and (2) both words in a given pair had to come from one of four serial locations: (a) Positions 1-12, (b) Positions 13-24, (c) Positions 25-36, or (d) Positions 37-48. This ensured that no words were paired from distant locations. The correct word in each pair occurred an equal number of times on both the right and the left, and the pairs were randomly distributed on the page.

\section{Questionnaire}

Six questions were typed on a separate sheet of paper. Two questions required responses on a rating scale and the other four required yes/no responses with elaborative explanations encouraged. The questions were designed to reveal strategies in memorizing the list such as visual imagery, word groupings for rehearsal, and awareness of rehearsal.

\section{Experimental Design and Procedure}

The design was a completely randomized ANOVA consisting of four different instructional groups, each with 16 subjects. Subjects were tested individually and were randomly assigned to one of four instructional groups: (1) Control (C), in which subjects were told only to remember the words for a later memory test; (2) JOR, wherein subjects were instructed to remember the words for a later JOR memory test which was then fully described; (3) JOP, in which subjects were asked to remember the words for a JOP test as described above; or (4) Recall (R), wherein subjects were informed to remember the words for a recall test in which they would be asked to write all the words in their exact order. This test was given to none of the subjects.

Appropriate instructions were read to the subjects, who were then informed that $\mathbf{4 8}$ words would appear on the computer screen, one at a time. Each word remained on the screen for $4 \mathrm{sec}$, followed by an interstimulus interval (ISI) of $4 \mathrm{sec}$. Each subject viewed four trial words prior to seeing the test list. Immediately after the list was presented, each subject was given both the JOP and the JOR tests, according to a randomly assigned order, as a counterbalancing procedure. Half of the subjects were given the JOP test followed by the JOR; the other half were given the JOR test followed by the JOP. The instructions were reviewed again (or read for the first time as determined by the instructional group) with appropriate examples. The subjects were told they had unlimited time to complete each test. After both memory tests had been completed, the subjects were asked to fill out the questionnaire.

\section{RESULTS}

\section{Judgment of Position Scores}

A one-way between-subjects ANOVA with the four groups was performed on transformed Pearson productmoment correlation coefficients (Filver \& Dunlap, 1987). An $r$ was obtained for each subject by correlating the actual position block with the subject's judged block. There was not a significant main effect for the instruction factor $[F(3,60)=.38]$. The respective means for the $\mathrm{C}$, JOR, JOP, and R groups were: $M=.3336 \pm .1596 ; M=$ $.3910 \pm .2577 ; M=.3584 \pm .3982 ;$ and $M=.2253$ $\pm .2572$

\section{Judgment of Recency Scores}

A one-way ANOVA was performed on the total correctly judged words. As was the case with the JOP scores, no significant main effect for instructions was found $[F(2,60)=.27]$. The means for the C, JOR, JOP, and R groups were: $M=13.06 \pm 2.81 ; M=13.00 \pm 1.86$ $M=13.69 \pm 2.15$; and $M=13.31 \pm 2.70$, respectively.

\section{Questionnaire}

Of the questions answered, informative data were extracted only from Questions 1 and 5. The categories of interest were: (1) percentage of subjects in each group who responded that they had been consciously rehearsing during the list presentation; (2) percentage of subjects in each group who indicated that they had grouped words together as a memory strategy; (3) of those who had grouped words, the percentage who had grouped 3-4 words; and (4) of those who had grouped words, the percentage who had grouped 5-6 words.

Qualitative assessment of the data showed that Group C subjects tried to group more words together and were consciously rehearsing more often than any of the other three instructional groups. Furthermore, the subjects of Group JOP and Group C reported efforts to group 5-6 words more often than those of Group JOR and Group R, who tended to rehearse words more often in groups of 3-4 words.

\section{DISCUSSION}

Subjects who received specific instructions about a temporal-order memory test performed no better than subjects who did not receive such 
instructions. Since instructions are believed to influence intentional or effortful processes directly (Hasher \& Zacks, 1979), this finding suggests that memory for temporal order may meet one of the criteria proposed for automatic processes. These results support earlier findings (Toglia \& Kimble, 1976; Zimmerman \& Underwood, 1968).

In contrast, however, are the studies reported by Michon and Jackson (1984), which demonstrated an advantage on temporal-order performance for subjects who received temporal-order instructions. They found that such instructions facilitated the recall of order information, but were detrimental to recognition performance. They also found that recognition instructions were detrimental to scores on the recall tests. Michon and Jackson proposed that temporal cues are useful only in tasks that require active reconstruction (i.e., recall), and are of little value in recognition tasks. They concluded that temporal-order memory is a deliberate process that requires the subject's attention. Other evidence that showed that rehearsal influences temporal-order encoding has been provided by Auday, Sullivan, and Cross (1988)

Although the results of the present experiment, in and of themselves, suggest no ambiguity, some of the difficulties with studying automatic and effortful processes are noteworthy with respect to other current findings. The first difficulty is the selection and administration of memory instructions. It may be that subjects invoke memory strategies that incorporate temporal cues as part of a general learning process. Of particular concern is the development of instructional sets that specifically encourage or discourage temporal order encoding, thus isolating the intentionality variable. It has been proposed that true incidental instructions and tasks insure that the learning is, in itself, incidental (NavehBenjamin \& Jonides, 1986). Such instructions have been implemented in studies of word frequency (Naveh-Benjamin \& Jonides, 1986; Sanders et al., 1987), category frequency (Williams \& Durso, 1986), and spatial location (Naveh-Benjamin, 1987). Perhaps even the mention of a general memory task (given to Group C) in the present study prevented the observation of differences among instructional groups. Development of effective tasks and instructions is a future challenge.

Another factor that seems to influence the observation of instructional effects is length of encoding time (Ellis \& Palmer, 1988; Naveh-Benjamin \& Jonides, 1986). Investigations of the notion of automaticity with regard to word frequency have led to the proposition that automatic encoding of word frequency may take place very rapidly, and thereafter may be resistant to further modification. The suggested time period of memory malleability is less than $4 \mathrm{sec}$. Since the present experiment used word exposure times of $4 \mathrm{sec}$, it is possible that this militated against differences among the instructional conditions that otherwise might have been realized. Research needs to be initiated to determine how exposure time interacts with instructions.

Finally, some have criticized the Hasher and Zacks (1979) criteria for automaticity and effort as being vague and unsatisfactory (Fisk, 1986; Naveh-Benjamin, 1987; Sanders et al., 1987). Current discussion of instructional manipulations speaks of intentionality rather than effort, with the implication that awareness is the critical factor (Sanders et al., 1987). In fact, the notion of all-or-none processes (i.e., completely automatic or effortful) has been rigorously challenged. Such criticism has subsequently been contested (Zacks, Hasher, \& Hock, 1986). The debate and evidence would suggest that memory for temporal order may simply be a process which is more or less automatic, depending upon where it is located on a continuum of effort (Naveh-Benjamin, 1987; Naveh-Benjamin \& Jonides, 1986).

The results of the present study, taken as a whole, provide evidence that temporal-order memory processes do meet one of the Hasher and Zacks (1979) criteria for automatic memory processes. At this point, it is probably not possible to provide a comprehensive test of the HasherZacks theory within a single experimental design, and therefore a number of isolated studies will be required to provide a critical mass of evidence with respect to each criterion they have proposed.

\section{REFERENCES}

Auday, B. C., Sullivan, C., \& Cross, H. A. (1988). The effects of constrained rehearsal on judgments of temporal order. Bulletin of the Psychonomic Society, 26, 548-551.

Ellis, N. R., \& Palmer, R. L. (1988). Instructional effects in memory for frequency of occurrence. Bulletin of the Psychonomic Society, 26 , 197-199.

Filver, N. C., \& DUNLAP, W. P. (1987). Averaging correlation coefficients: Should Fisher's Z transformation be used? Journal of Applied Psychology, 72, 146-148.

FisK, A. D. (1986, February). Frequency encoding is not inevitable and is not automatic: A reply to Hasher and Zacks. American Psychologist, p. 215.

HASHER, L., \& ZACKs, R. T. (1979). Automatic and effortful processes in memory. Journal of Experimental Psychology: General, 108 356-388.

Hyde, T. S., \& Jenkins, J. J. (1969). Differential effects of incidental tasks on the organization of recall of a list of highly associated words. Journal of Experimental Psychology, 82, 472-481.

McCoRmaCK, P. D. (1981). Temporal coding by young and elderly adults: A test of the Hasher-Zacks model. Developmental Psychology, 17, 509-515.

McCormack, P. D. (1982). Temporal coding and study-phase retrieval in young and elderly adults. Bulletin of the Psychonomic Society, 20, 242-244.

Michon, J. A., \& JACKson, J. L. (1984). Attentional effort and cognitive strategies in the processing of temporal information. Annals of the New York Academy of Sciences, 423, 298-321.

Naveh-Benjamin, M. (1987). Coding of spatial location information: An automatic process? Journal of Experimental Psychology: Learning, Memory, \& Cognition, 13, 595-605.

Naveh-Benjamin, M., \& Jonides, J. (1986). On the automaticity of frequency coding: Effects of competing task load, encoding strategy, and intention. Journal of Experimental Psychology: Learning, Memory, \& Cognition, 12, 378-386.

Paivio, A., Yuille, J. C., \& Madigan, S. A. (1968). Concreteness, imagery, and meaningfulness values for 925 nouns. Journal of Experimental Psychology, 76, 1-25.

Palermo, D. S., \& Jenkins, J. J. (1964). Word association norms. Minneapolis: University of Minnesota Press.

Sanders, R. E., Gonzalez, E. G., MurPhy, M. C., Liddle, C. L., \& VITINA, J. R. (1987). Frequency of occurrence and the criteria for automatic processing. Journal of Experimental Psychology: Learning, Memory, \& Cognition, 13, 241-250.

THORNDIKE, E. L., \& LORGE, I. (1944). The teacher's wordbook of 30,000 words. New York: Columbia University Press.

Toglia, M. P., \& Kimble, G. A. (1976). Recall and use of serial position information. Journal of Experimental Psychology: Human Learning \& Memory, 21, 437-484.

Tulving, E., \& Madigan, S. A. (1970). Memory and verbal learning. Annual Review of Psychology, 21, 437-484.

TzENG, O. J. L. (1976). A precedence effect in processing of verbal information. American Journal of Psychology, 89, 577-599.

Tzeng, O. J. L., \& CotTon, B. (1980). A study-phase retrieval model of temporal coding. Journal of Experimental Psychology: Human Learning \& Memory, 6, 705-716.

Tzeng, O. J. L., LeE, A. T., \& WeTzel, C. D. (1979). Temporal coding in verbal information processing. Journal of Experimental Psychology: Human Learning \& Memory, 5, 52-64.

Williams, K. W., \& Durso, F. T. (1986). Judging category frequency: Automaticity or availability? Journal of Experimental Psychology: Learning, Memory, \& Cognition, 12, 387-396.

WinOGRad, E., \& Soloway, R. M. (1985). Reminding as a basis for temporal judgments. Journal of Experimental Psychology, 11, 262-271.

Zacks, R. T., Hasher, L., Allen, J. W., Sanft, H., \& Rose K. C. (1984). Is temporal order encoded automatically? Memory \& Cognition, 12, 387-394.

ZACKs, R. T., HASHER, L., \& Hock, H. S. (1986, February). Inevitability and automaticity: A response to Fisk. American Psychologist, p. 216.

ZIMmerman, J., \& Underwood, B. J. (1968). Ordinal position knowledge within and across lists as a function of instructions in freerecall learning. Journal of General Psychology, 79, 301-307.

(Manuscript received October 24, 1988.) 